\title{
TRATAMENTO COM ÁCIDO FOSFÓRICO EM CAULINITA E INTERCALAÇÃO COM FONTES DE FOSFATO
}

\section{A. C. GLUITZ ${ }^{1}$, A. PRASNIEWISKI ${ }^{1}$, J. C. K. NEVES ${ }^{2}$, L. ZATTA ${ }^{1}$, C. R. BUDZIAK- PARABOCZ ${ }^{1}$}

${ }^{1}$ Universidade Tecnológica Federal do Paraná, Campus Pato Branco, Departamento de Química

${ }^{2}$ Universidade Tecnológica Federal do Paraná, Campus Curitiba, Departamento de Mecânica

E-mail para contato: adrianagluitz@hotmail.com

\begin{abstract}
RESUMO - A caulinita é um argilomineral que possui estrutura baseada no empilhamento de camadas, sendo possível realizar a incorporação química de uma molécula estranha entre estas, tal processo é denominado como intercalação. Outra modificação na caulinita é a ativação ácida, a qual altera composição química e sua estrutura, resultando no aumento da área superficial e da porosidade da caulinita. Neste trabalho foi realizado o tratamento ácido a fim de facilitar o processo de intercalação de moléculas de fosfato na estrutura da caulinita. O tratamento com ácido alterou a estrutura cristalina da caulinita, porém não se observou pela técnica de DRX a intercalação devido à baixa concentração dos agentes intercalantes empregadas no processo. Observou-se por IVTF variações nas intensidades e deslocamentos de bandas, isso se deve possivelmente a lixiviação do tratamento ácido.
\end{abstract}

\section{INTRODUÇÃO}

A caulinita é um argilomineral, constituído de silicatos hidratados de alumínio (Zhang et al., 2011) e caracterizada como um composto lamelar por possuir sua estrutura formada pelo empilhamento das camadas compostas por unidades de sílica $\left(\mathrm{SiO}_{4}\right)$ e alumina $\left(\mathrm{Al}_{2}(\mathrm{OH})_{6}\right)$ (Matusik et al., 2013). Devido a sua estrutura em camadas é possível realizar a incorporação química de uma molécula estranha na sua unidade estrutural, sendo este processo chamado de intercalação (Lopes et al., 2003).

Outra modificação na caulinita é o tratamento com ácido, conhecido como ativação ácida onde são empregados ácidos inorgânicos. No processo de ativação ocorre alteração da composição química e de sua estrutura, resultando no aumento da área superficial e da porosidade da caulinita (Panda et al., 2010).

Alguns trabalhos da literatura relatam o processo de intercalação da caulinita com fosfato, este materiais apresentam diferentes aplicações, uma que se destaca, é o emprego deste tipo de material como fertilizante à base de fósforo de liberação lenta (Zhang et al., 2011).

Com o objetivo de aumentar a área superficial e a porosidade da caulinita afim de facilitar o processo de intercalação, inicialmente foi realizado o processo de ativação com o ácido fosfórico, após este processo, o material obtido foi submetido ao processo de intercalação com precursor de fosfato. 
Acredita-se que os ânions fosfatos oriundos do ácido fosfórico possam ser retidos na estrutura da caulinita durante o processo da ativação ácida, o que pode contribuir com o objetivo do trabalho de obtenção de materiais com função de fertilizante, baseados nos processos de ativação ácida e intercalação.

\section{METODOLOGIA}

\subsection{Preparo da Amostra}

A caulinita utilizada é proveniente do Rio Capim do estado do Pará - Brasil. A caulinita foi seca em estufa a $100{ }^{\circ} \mathrm{C}$ durante 2 horas, posteriormente foi triturada e peneirada (80 mesh).

\subsection{Tratamento com Ácido Fosfórico}

O tratamento foi realizado conforme descrito por Ayodele (2013). Utilizou-se soluções de ácido fosfórico em duas concentrações, 5 e 10 mol.L $\mathrm{L}^{-1}$, os materiais obtidos foram nomeados como Cau-5M e Cau-10M, respectivamente.

Em um balão de fundo redondo pesou-se 50 gramas de caulinita e adicionou-se 200 $\mathrm{mL}$ de solução de ácido fosfórico. $\mathrm{O}$ balão foi acoplado a um condensador de refluxo a uma temperatura de $110^{\circ} \mathrm{C}$ durante 2 horas. Após o término, a reação foi imediatamente arrefecida pela adição de água gelada. A caulinita ativada foi filtrada e lavada com água destilada até pH próximo a 7, com o objetivo de remover o ácido não consumido. Posteriormente as amostras foram secas em estufa a $110{ }^{\circ} \mathrm{C}$ por 12 horas. Decorrido o período de secagem as amostras foram trituradas com almofariz e pistilo de ágata.

\subsection{Intercalação com Fosfato}

A intercalação da caulinita com fosfato foi realizada nas amostras de caulinita pura (Cau-0) e materiais obtidos pela ativação com ácido fosfórico, Cau-5M e Cau-10M. Cada amostra foi intercalada com dois precursores diferentes de fosfato, sendo o fosfato de potássio monobásico $\left(\mathrm{KH}_{2} \mathrm{PO}_{4}\right)$ e o fosfato de potássio bibásico anidro $\left(\mathrm{K}_{2} \mathrm{HPO}_{4}\right)$.

Realizou-se o processo de intercalação de acordo com uma adaptação da metodologia descrita por Unuabonah, Adebowale e Olu-Owolabi (2007) pela intercalação via-úmida. Para cada 6 gramas de amostra foram adicionados $120 \mathrm{~mL}$ de solução a 0,001 mol.L-1 dos reagentes de fosfato $\left(\mathrm{KH}_{2} \mathrm{PO}_{4}\right.$ e $\left.\mathrm{K}_{2} \mathrm{HPO}_{4}\right)$.

As amostras Cau-0 intercalada com $\mathrm{KH}_{2} \mathrm{PO}_{4}(\mathrm{Cau}-0 \mathrm{~K})$ e com $\mathrm{K}_{2} \mathrm{HPO}_{4}(\mathrm{Cau}-0 \mathrm{~K} 2)$, a Cau-5M intercalada com $\mathrm{KH}_{2} \mathrm{PO}_{4}(\mathrm{Cau}-5 \mathrm{MK})$ e com $\mathrm{K}_{2} \mathrm{HPO}_{4}(\mathrm{Cau}-5 \mathrm{MK} 2)$ e a Cau-10M intercalada com $\mathrm{KH}_{2} \mathrm{PO}_{4}(\mathrm{Cau}-10 \mathrm{MK})$ e com $\mathrm{K}_{2} \mathrm{HPO}_{4}(\mathrm{Cau}-10 \mathrm{MK} 2)$ foram agitadas em agitador magnético durante 24 horas e posteriormente foram filtradas. Em seguida foram levadas para secagem em estufa a $110^{\circ} \mathrm{C}$ por 24 horas. As amostras secas foram moídas em gral e pistilo de ágata.

\subsection{Caracterização}




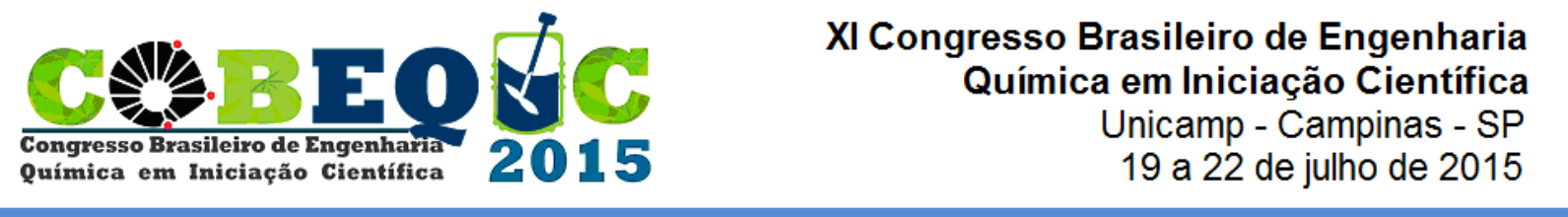

Espectroscopia de Infravermelho por Transformada de Fourier: A caracterização através da Espectroscopia de IVTF foi realizada em um espectrofotômetro Perkin Elmer, modelo Frontier. Cerca de $1 \mathrm{mg}$ de amostra foi homogeneizada com aproximadamente $99 \mathrm{mg}$ de brometo de potássio $(\mathrm{KBr})$ de grau espectroscópico, ambos previamente secos para a confecção das pastilhas a serem analisadas. Os espectros foram registrados no modo de transmitância na faixa de $4000 \mathrm{~cm}^{-1}$ a $400 \mathrm{~cm}^{-1}$ com resolução de $2 \mathrm{~cm}^{-1}$ e acumulação de 16 varreduras.

Difratometria de Raios X: As análises de Difração de Raios X foram realizadas em um difratômetro da Shimadzu, modelo XRD 7000. Utilizando radiação $\mathrm{Cu}-\mathrm{K} \alpha$ com ângulos de varredura de $3^{\circ}$ a $60^{\circ}$ de $2 \theta$, com um passo de 0,02 . A análise de DRX permitiu a identificação da composição mineralógica das amostras e através desta análise foi possível obter a distância interlamelar afim de verificar se ocorreu aumento deste parâmetro em relação a caulinita pura, e a taxa de intercalação da caulinita com o objetivo de constatar se ocorreu efetivamente a intercalação das moléculas de interesse (Li et al. 2009).

\section{RESULTADOS E DISCUSÃO}

\subsection{Espectroscopia de Infravermelho por Transformada de Fourier (IVTF)}

A figura 1 mostra os espectros da caulinita pura, caulinita tratada com ácido e intercalada.

Figura 1 - Espectro de IVTF

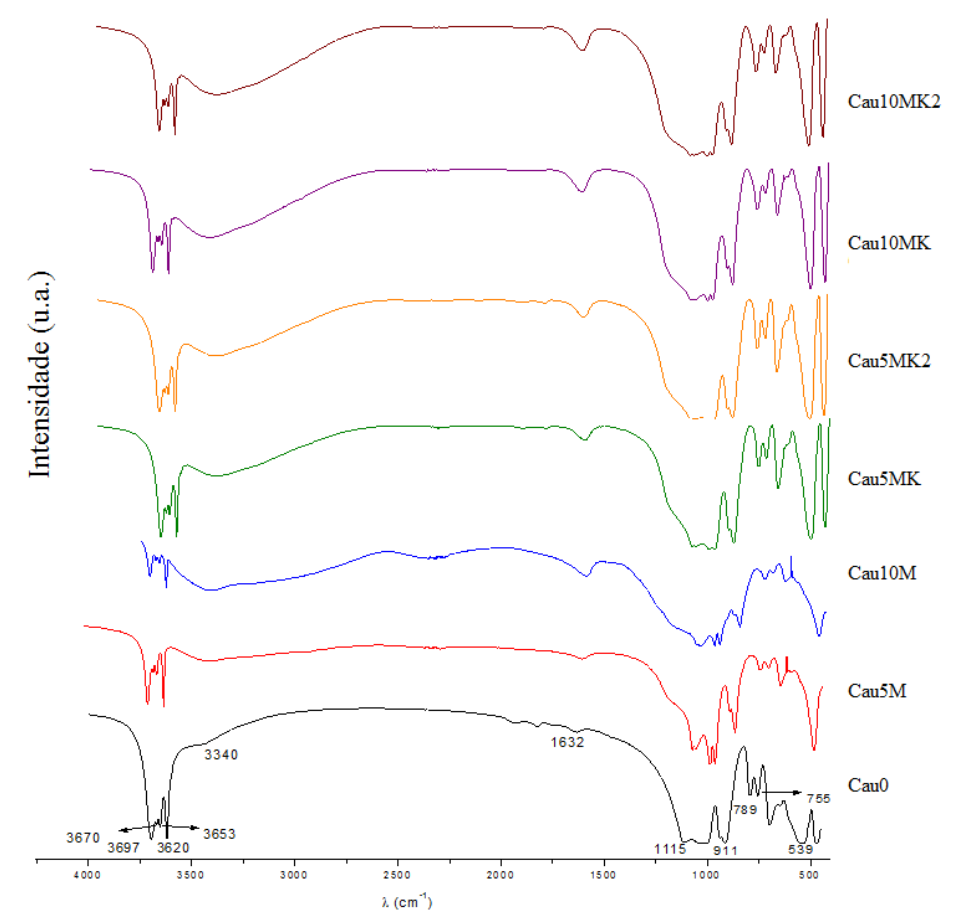

As vibrações na faixa de 3670,3697 e $3653 \mathrm{~cm}^{-1}$ da caulinita pura representam as hidroxilas localizadas na superfície interna da caulinita (Matusik et al., 2013; Sahnoun; Bouaziz, 2012), proveniente do estiramento Al-OH (Panda et al., 2010). No entanto a banda 


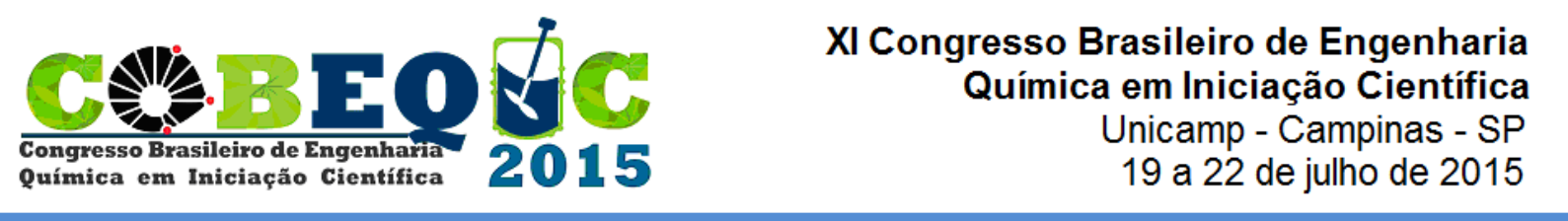

$3620 \mathrm{~cm}^{-1}$ é referente as hidroxilas internas (Frost et al., 2000; Matusik et al., 2013), ou seja, são as hidroxilas da superfície interlamelar da caulinita (Li et al., 2009) que se encontram entre as suas camadas tetraédricas e octaédricas (Ayodele, 2013).

Nessa mesma região, para os espectros da caulinita tratada e intercalada observa-se que a única banda que permanece com intensidade próxima à do precursor de caulinita pura é a banda em $3620 \mathrm{~cm}^{-1}$, pois as hidroxilas internas não participam das interações de hidrogênio com as moléculas intercalantes (Li et al., 2009), como o ocorre com as hidroxilas da superfície da caulinita (Cheng et al., 2010).

De acordo com Panda et al. (2010) a banda na região de $3340 \mathrm{~cm}^{-1}$, para a caulinita pura, representa a adsorção de água na superfície da caulinita e a banda em $1634 \mathrm{~cm}^{-1}$ é proveniente da vibração de flexão da água livre na superfície da sílica.

Nos espectros da caulinita ativada e intercalada é possível observar um aumento na intensidade dos picos em $3340 \mathrm{~cm}^{-1}$ e $1634 \mathrm{~cm}^{-1}$, ou seja, uma maior quantidade de água nas amostras. Esse fato pode ser justificado devido ao processo de lixiviação (Panda et al., 2010) decorrente tanto do processo de tratamento ácido quanto do processo de intercalação.

As vibrações na região de $1115 \mathrm{~cm}^{-1}$, representam o grupamento -SiO da superfície da caulinita (Panda et al., 2010; Sahnoun; Bouaziz, 2012). Observa-se que nos espectros da caulinita tratada e intercalada essa região se mantém, quase não sofrendo deslocamento (Faria et. al, 2009; Elbokl e Detellier, 2008).

Segundo Ayodele (2013) as bandas 910, 795 e $755 \mathrm{~cm}^{-1}$ representam, respectivamente as vibrações Al-Al-OH, Al-Mg-OH, Si-O-Al da folha da argila e a alta intensidade da banda $910 \mathrm{~cm}^{-1}$ é devido as vibrações dos grupos hidroxila. A banda em $539 \mathrm{~cm}^{-1}$ também representa as alterações de Si-O-Al, e observa-se modificações nesta região durante os tratamentos, provavelmente deve-se a lixiviação das espécies presentes durante o tratamento ácido (Sahnoun; Bouaziz, 2012).

\subsection{Difratometria de Raios $X$}

Os difratogramas de raios $\mathrm{X}$ da caulinita pura, caulinita tratada com ácido fosfórico a 5 $\mathrm{mol} / \mathrm{L}$, e caulinita tratada com ácido fosfórico a $5 \mathrm{~mol} / \mathrm{L}$ e intercalada com $\mathrm{KH}_{2} \mathrm{PO}_{4}$ estão representados na Figura 2.

Figura 2 - Difratogramas de raios $\mathrm{X}$ 


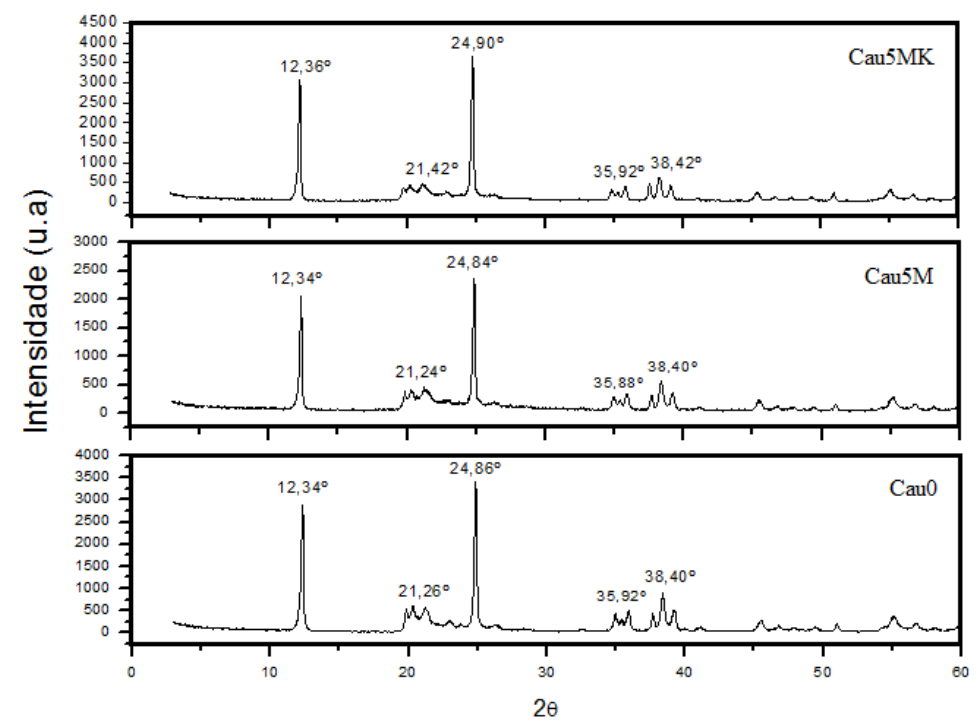

Através do difratograma da caulinita pura pode-se observar picos agudos e bem definidos, indicando um argilomineral com alto grau de cristalinidade (Gardolinski; Lagaly, 2005).

O difratograma da caulinita pura apresenta dois picos característicos de caulinita, em aproximadamente $12^{\circ}$ e $25^{\circ}$ de $2 \theta$ correspondente a reflexão de [001], os outros picos observados no difratograma variam de acordo com a origem da caulinita (Ayodele, 2013; Panda et al., 2010).

Após o tratamento ácido verifica-se uma diminuição na intensidade do pico em aproximadamente $12^{\circ}$ de $2 \theta$. De acordo com Panda et al. (2010) isso ocorre devido a desordem estrutural que ocorreu após o tratamento ácido, afetando o carácter cristalino da argila.

Aplicando a lei de Bragg obteve-se a distância interlamelar, no qual a Cau0 apresentou-se com 7,16 ̊́, a Cau5M também com 7,16 ̊̊́ e a Cau5MK com 7,15 ̊́. Desta maneira pode se observar que nem o tratamento ácido, nem a intercalação ocasionaram um aumento na distância interlamelar da caulinita, indicando que os precursores baseados em fosfato podem estar interagindo nas bordas e na região superficial do argilomineral.

\section{CONCLUSÃO}

Com este trabalho foi possível observar as alterações estruturais ocasionadas pelo tratamento ácido e posteriormente pela intercalação com moléculas de fosfato.

No entanto, observou-se através da análise de DRX, que a intercalação de fosfato não ocorreu entre as camadas interlamelares da caulinita, provavelmente devido a baixa concentração dos reagentes de $\mathrm{KH}_{2} \mathrm{PO}_{4}$ e $\mathrm{K}_{2} \mathrm{HPO}_{4}$ utilizados, mas possivelmente se ligaram aos grupamentos das hidroxilas externas da caulinita, tal fato foi comprovado pelo IVTF nas regiões de 3670,3697 e $3653 \mathrm{~cm}^{-1}$. O tratamento ácido pode não ter sido suficiente para facilitar o processo de intercalação das moléculas de fosfato. Concentrações maiores de $\mathrm{KH}_{2} \mathrm{PO}_{4}$ e $\mathrm{K}_{2} \mathrm{HPO}_{4}$, serão utilizadas para verificar se a intercalação ocorre na caulinita. 


\section{REFERÊNCIAS}

AYODELE, O. B. Effect of phosphoric acid treatment on kaolinite supported ferrioxalate catalyst for the degradation of amoxicillin in batch photo-Fenton process. App. Clay Sci., v. 72, p. 74-83, 2013.

CHENG, H.; LIU, Q.; YANG, J.; MA, S.; FROST, R. L. The thermal behavior of kaolinite intercalation complexes - A review. Thermochimica Acta, v. 545, p. 1-13, 2012.

ELBOKL, T. A; DETELLIER, C. Intercalation of cyclic imides in kaolinite. $J$, coll. \& Interface Sci. v. 323, n. 2, p. 338-48, 15 jul. 2008.

FARIA, E. H.; LIMA, O. J.; CIUFFI, K. J.; NASSAR, E. J.; VICENTE, M. A.; TRUJILLANO, R.; CALEFI, P. S. Hybrid materials prepared by interlayer functionalization of kaolinite with pyridine-carboxylic acids. J. Coll. \& Interf. Sci., v. 335 , p. 210-215, 2009.

FROST, R. L.; KRISTOF, J.; HORVATH, E.; KLOPROGGE, J. T. Effect of water on the formamide-intercalation of kaolinite. Spectroc. acta: Molec. \& biomolec. spectr., v. 56A, p. 1711-29, 2000.

GARDOLINSKI, J. E. F. C.; LAGALY, G. Grafted organic derivatives of kaolinite: II. Intercalation of primary n-alkylamines and delamination. Clay Min., v. 40, p. 547-556, 2005.

LI, Y.; SUN, D.; PAN, X.; ZHANG, B. Kaolinite intercalation precursors. Clays \& Clay Min., v. 57, p.779-786, 2009.

LOPES, P.C.; Dias, F. A; Silva, L. R. D. da. Decomposition kinetics by thermogravimetry for the intercalation of kaolin with dimethylsulphoxide. Mat. Lett., v. 57, p. 3397-3401, 2003

MATUSIK, J.; KŁAPYTA, Z.; OLEJNICZAK, Z. NMR and IR study of kaolinite intercalation compounds with benzylalkylammonium chlorides. App.Clay Sci., v. 83-84, p. 426-432, 2013.

PANDA, A. K.; MISHRA, B. G.; MISHRA, D. K.; SINGH, R. K. Effect of sulphuric acid treatment on the physico-chemical characteristics of kaolin clay. Coll. \& Surf.: Physic. \& Eng. Aspec., v. 363, p. 98-104, 2010.

SAHNOUN, R. D.; BOUAZIZ, J. Sintering characteristics of kaolin in the presence of phosphoric acid binder. Ceram. Intern., v. 38, n. 1, p. 1-7, 2012.

UNUABONAH, E. I.; ADEBOWALE, K. O.; OLU-OWOLABI, B. I. Kinetic and thermodynamic studies of the adsorption of lead (II) ions onto phosphate-modified kaolinite clay. J. hazard. mater., v. 144, p. 386-95, 2007 
ZHANG, Q.; TONGAMP, W.; SAITO, F. Mechanochemical synthesis of kaolin- $\mathrm{KH}_{2} \mathrm{PO}_{4}$ and kaolin- $\mathrm{NH}_{4} \mathrm{H}_{2} \mathrm{PO}_{4}$ complexes for application as slow release fertilizer. Powd. Tech., v. 212, p. 354-358, 2011. 